\title{
Editorial \\ Child language research: building on the past, looking to the future
}

Twenty years ago, in 1974, the first volume of the Fournal of Child Language was published. This special 2oth anniversary issue brings together papers by a number of scholars who, coming from various perspectives, present research that not only builds upon the scholarly achievements of the past but also points the way forward to new lines of enquiry.

Over the last 25 years or so a great deal has been achieved descriptively, methodologically and theoretically in the area of child language research. We now know much more than we did at the beginning of the 1970 , for example, about the role of adult input (e.g. Snow, I986; Shatz, Hoff-Ginsberg \& MacIver, 1989; Richards \& Robinson, I993); about individual differences in the course of language acquisition (e.g. Bates, Bretherton \& Snyder, I 980; Nelson, 1981; Lieven, Pine \& Dresner Barnes, 1992); about children's ability to use language in connected discourse (e.g. Karmiloff-Smith, 1986; Peterson \& Dodsworth, 1991); and to adapt their message to the needs of their listener (e.g. Menig-Peterson, I975; Perner \& Leekam, 1986).

The earlier heavy focus on the acquisition of English has been supplemented not only by descriptions of the acquisition of a wide range of the world's languages (e.g. Korean: Clancy, 1989; Tamil: Vaidyanathan, 1991; Turkish: Aksu-Koç, 1988; Warlpiri: Bavin \& Shopen, 1985; and see Slobin, I 985 (Vol. I) and 1993 for studies of some 20 languages) but also by crosslinguistic studies which specifically look for comparisons and contrasts in the course of acquisition of languages with differing phonological, morphological or syntactic characteristics (e.g. Slobin, 1985 (Vol. II); MacWhinney $\&$ Bates, I 989; Weist, Wysocka \& Lyytinen, 1991). This crosslinguistic perspective is particularly important, not just because it helps to prevent the study of language acquisition being too anglocentric but, much more significantly, because of its theoretical value. Since all normally-developing children have the potential to acquire any of the world's languages, regardless of their typology, any theory that seeks to explain the mechanisms of language acquisition must be able to account for ALL the patterns of development that researchers identify, not just those in the world's major languages. These crosslinguistic studies have begun the task of identifying those aspects of acquisition that are universal and those that are language-specific. For example, while studies of English and other Indo-European languages suggest that the passive is a relatively late acquisition (e.g. Maratsos, Kuczaj, Fox \& Chalkley, 1979), studies of a number of non-Indo-European langu- 
ages, such as Turkish, Sesotho and Zulu (Demuth, I 990) show comparatively EARLY acquisition of the passive-highlighting the importance of the interaction between a particular grammatical structure and the linguistic system as a whole, including its pragmatic and communicative aspects.

As far as methodology is concerned, new research paradigms have made it possible to study the neonate's responsiveness to speech sounds (e.g. Moon, Bever \& Fifer, 1 992). The increasingly widespread use of videotaped data has strengthened the validity of studies of early language which seek to relate grammatical form to communicative function. Crosslinguistically-stimulated work on mean length of utterance - one of the most basic and taken-forgranted yardsticks in language acquisition research - has drawn attention to the limitations of this measure (e.g. Dromi \& Berman, 1982; Hickey, I991). And the establishment of the CHILDES database, with its related computercoding system for child language data, has enormously enhanced access to the invaluable corpora of data that have been collected by child language researchers around the world (MacWhinney, I99 I).

Turning to theoretical advances, the last quarter of a century has seen new and highly productive theories emanate from both linguistics and psychology, e.g. government and binding (Chomsky, I98 I, I986) with its related notion of parameter setting (see, for example, Atkinson, I992); modularity (e.g. Fodor, I983); relevance theory (Sperber \& Wilson, I 986); semantic bootstrapping (e.g. Pinker, I984, I989); and connectionism - or parallel distributed processing (e.g. McClelland \& Rumelhart, I986). Some of these theories have been developed specifically to provide explanations for children's language-learning abilities; others have wider or more abstract aims, such as modelling human learning mechanisms or providing a universallyapplicable account of grammatical structure. All these theories have been adduced by various psycholinguists to provide the theoretical underpinning for their investigations into child language, but, interestingly, it is now also the case that the empirical data from acquisition studies are sometimes used to test the validity of linguistic hypotheses that do not have a specifically acquisitionist focus (see, for example, pp. 253-4 below).

Despite all the progress that has been made, it is clear that much more remains to be done. This is partly because the task itself has become more ambitious : the heightened importance of universal grammar within linguistic theory means that many researchers now want language acquisition data to answer questions not only about psycholinguistic mechanisms within the individual learner but also about the inter-relatedness of different linguistic categories within the grammatical system itself. Central, related questions are: how much and what kind of linguistic knowledge is innate? Whatever linguistic knowledge is innate must necessarily be part of universal grammar. So commonalities in the acquisition of languages from typologically different 
groups are important not just for their intrinsic interest but also for the light they shed on linguistic innateness and universality.

The papers gathered together in this volume all necessarily build on the work of earlier language researchers but they also point the way forward to new research avenues that will be explored during the next decade. A characteristic that they all share is that they open up new lines of enquiry or provide new tools for researchers, pointing the way forward to further productive work in child language.

Competing strands of theory are outlined in the opening contribution by Martin Braine. This paper sets the scene for the rest of the volume because it highlights the kinds of question that descriptive studies need to address, whether the researcher is coming from a nativist or empiricist/interactionist perspective. Braine identifies two tasks of developmental theory: (I) to discover what innate cognitive and linguistic primitives there are - this is the starting point of many linguists; and (2) to provide an account of development within the individual - the starting point of many psychologists. He points out that the second task is a necessary adjunct to the first, since positing a set of cognitive or linguistic primitives and leaving the rest to neurophysiological maturation is not enough. Revealing similarities between Piaget's assimilation-accommodation mechanism and more recent 'bootstrapping' explanations (e.g. Pinker, 1984), he suggests a means by which children can extend their linguistic competence by moving from prototypical exemplars of a category to more peripheral ones. Such a learning mechanism would be economical because it would do away with the need for syntactic primitives and would explain how different mappings between semantic and syntactic categories arise in different languages.

The next two articles deal with aspects of phonology. Oller, Eilers, Steffens, Lynch \& Urbano aim to discover the ways in which experience, such as sensory stimulation, interacts with the innate drive to babbling. Their comparisons of the production of canonical syllables in the babbling of infants born either prematurely or at full term into families with either a low or middle socioeconomic background reveal a complex interaction among neurophysiological maturation, perceptual and motoric experience and input from the environment. The authors suggest that in order to expand our understanding of the stages of early vocal development it will be necessary to seek a characterization of the mechanism that might underlie the differences which have been identified in the onset of babbling. In a study of Dutchspeaking children, Wijnen, Krikhaar \& den Os draw together two wellknown - and apparently universal - facts about early child language: weak syllable omission in polysyllabic words and the omission of grammatical morphemes such as determiners. Using the theoretical framework provided by metrical phonology, they provide a coherent, unified explanation for these two phenomena. They postulate that the strong-weak trochaic stress pattern 
is a universal of human perceptual and motor performance. If this is the case, the obvious question that arises is how do children move from an innate trochaic stress pattern to the language-specific stress rules of their mother tongue? Research on the acquisition of languages with different stress rules from Dutch and English will be needed to provide answers to this question.

Aspects of vocabulary acquisition are treated in the following two papers. In a large-scale study with over 1,800 children, Bates and seven colleagues take forward the research into individual differences in the style of language acquisition that has been stimulated by Nelson's ( 1973) distinction between 'referential' and 'expressive' learners. Such differences are of great theoretical interest because they cannot be explained by a maturation account that simply postulates a different RATE of acquisition along the same path. We have to consider what kind of language-learning mechanisms could lead to different language styles. Taking account of Pine \& Lieven's ( 1990) work which suggested that earlier studies had confounded stylistic variation and differential rates of development, Bates et al. seek to disentangle the confound and conclude that there is in fact no relationship between early referential style and precocious language development. The period of maximum individual variation in vocabulary size appears to be between $1 ; 4$ and 2;0 when children typically have lexicons of between 10 and 50 words. The study reveals a different developmental course for different parts of speech, with changing proportions of common nouns, predicates (verbs and adjectives) and grammatical function words indicating shifts in emphasis in the child's language use from reference to predication to grammar. Systematic relationships - regardless of age - between the size of the lexicon and its composition in terms of word classes provide some evidence for 'critical mass' accounts of vocabulary development. There is now a need for comparable work on other languages to provide information on the extent to which these findings are universal or language-specific. And the task of EXPLAINING the individual differences still lies ahead.

Golinkoff; Mervis \& Hirsh-Pasek note that a number of different principles have been proposed in attempts to explain How children acquire their vocabularies rapidly and apparently effortlessly. Here, they take six principles and integrate them into a coherent set, organized in two developmental tiers. These principles would allow room for individual differences in learning rate and style. Like Bates et al., Golinkoff et al. provide evidence that the composition of the lexicon and the manner of acquiring vocabulary at a given stage might be specifically related to the number of words known at that point. Further studies will be needed to validate the developmental aspects of the set of principles and particularly to establish whether they have a fixed order of appearance.

Morphological and syntactic development feature in the next three papers. All three use evidence from children's speech errors to gain a window into the 
mechanism of acquisition. A widely-attested type of error is the overextension of some pronoun case forms. By looking for a phonetic core in English pronouns and determiners and finding it in he/him/his and they/ them/their but not in $I / m e / m y$ or she/her, Rispoli provides at least a partial explanation for the asymmetry in the overextension of different pronominal forms. Once again, new research with data from other languages - particularly those where some of the pronouns share a common phonetic core and others in the same paradigm do not - is needed to test this hypothesis further.

Just as Rispoli integrates phonetics and morphology, so Kim, Marcus, Pinker, Hollander \& Coppola integrate inflectional morphology and grammar, by showing that children respond differentially to the morphology of irregular nouns and verbs depending upon the identity of the head in the underlying grammatical structure within which the root morpheme is embedded. For example, having first overgeneralized the plural, which leads to forms like tooths, children then produce not only teeth but also, when appropriate, expressions such as two sabre-tooths. Kim et al.'s head-based theory provides an economical explanation since only information about the morphology of the root needs to be stored in the lexicon; grammatical structure can be handled by regular grammatical rules which are accessed before the surface morphology. A further advantage of this account is that it is apparently consistent with adults' processing of morphologically irregular forms and so allows for continuity of development.

In a paper that focuses on the errors that children make in their acquisition of interrogatives, Radford reanalyses the data in Klima \& Bellugi's classic I 966 article within a government and binding framework. He traces development through Klima \& Bellugi's three stages to adult English, attempting to minimize developmental discontinuity. He compares three different GB-based grammatical interpretations of the data: a head analysis, an adjunction analysis, and a specifier analysis. These formulations offer interesting ways forward: it is clear that crosslinguistic accounts of interrogative acquisition will help to show which of these competing theoretical positions has the most universal descriptive and explanatory adequacy.

The final paper by Foster-Cohen examines the interface between syntax and pragmatics by analysing data concerning children's interpretation of pronominal expressions. Binding theory (in Reinhart's I 983 version) gives a unitary account of these, whether they function as anaphors, pronouns or referring expressions. The problem from an acquisitionist point of view is that a number of experimental studies have shown children performing very differently on the three types. Foster-Cohen enlists Sperber \& Wilson's (1986) relevance theory to explore how pragmatic characteristics of this single grammatical category might lead to children's erroneous interpretations of pronominal reference. The study suggests a way in which future 
work in the area might remove the experimental confound between children's syntactic ability and their pragmatic understanding.

The papers gathered together in this volume show how a judicious combination of an appropriate theoretical framework and sensitivelyanalysed empirical data can provide satisfying answers to issues in child language development. At the same time they stimulate fresh questions. The exploration of these 'growing points' will no doubt contribute to the vitality of research in child language for the rest of the decade.

\section{REFERENCES}

Aksu-Koc, A. (1988). The acquisition of aspect and modality. The case of past reference in Turkish. Cambridge: C.U.P.

Atkinson, M. (1 992). Children's syntax : an introduction to principles and parameters theory. Oxford: Blackwell.

Bates, E., Bretherton, I. \& Snyder, L. (1980). From first words to grammar : individual differences and dissociable mechanisms. Cambridge: C.U.P.

Bavin, E. L. \& Shopen, T. A. (1985). Children's acquisition of Warlpiri: comprehension of transitive sentences. Journal of Child Language 12, 597-6 10.

Chomsky, N. (1981). Lectures on government and binding. Dordrecht: Foris.

- (1986). Barriers. Cambridge, MA : MIT Press.

Clancy, P.(1989). Form and function in the acquisition of Korean wh- questions. Journal of Child Language 16, 323-47.

Demuth, K. (1 990). Subject, topic and Sesotho passive. Fournal of Child Language 17, 67-84.

Dromi, E. \& Berman, R. A. (1982). A morphemic measure of early language development: data from modern Hebrew. Fournal of Child Language 9, 403-24.

Fodor, J. A. (1983). The modularity of mind. Cambridge, MA: MIT Press.

Hickey, T. (1991). Mean length of utterance and the acquisition of Irish. Fournal of Child Language 18, 553-69.

Karmiloff-Smith, A. (1986). Some fundamental aspects of language development after age 5 . In P. Fletcher \& M. Garman (eds), Language acquisition (2nd edn). Cambridge: C.U.P.

Klima, E. S. \& Bellugi, U. (1966). Syntactic regularities in the speech of children. In J. Lyons \& R. J. Wales (eds), Psycholinguistic Papers. Edinburgh: Edinburgh University Press.

Lieven, E. V. M., Pine, J. M. \& Dresner Barnes, H. (1992). Individual differences in early vocabulary development: redefining the referential-expressive distinction. Fournal of Child Language 19, 287-310.

McClelland, J. L. \& Rumelhart, D. E. (eds) (1986). Parallel distributed processing : explorations in the microstructure of cognition. Cambridge, MA: MIT Press.

MacWhinney, B. (I991). The CHILDES project: computational tools for analyzing talk. Hillsdale, NJ: Erlbaum.

MacWhinney, B. \& Bates, E. ( 1989 ). The crosslinguistic study of sentence processing. Cambridge: C.U.P.

Maratsos, M., Kuczaj, S., Fox, D. \& Chalkley, M. A. (1979). Some empirical studies in the acquisition of transformational relations: passives, negatives and the past tense. In W. A. Collins (ed.), Children's language and communications. Hillsdale, NJ: Erlbaum.

Menig-Peterson, C. L. (1975). The modification of communicative behavior in preschoolaged children as a function of the listener's perspective. Child Development 46, 1015-18.

Moon, C., Bever, T. G. \& Fifer, W. P. (1992). Canonical and non-canonical syllable discrimination by two-day-old infants. Fournal of Child Language 19, 1-17.

Nelson, K. (1973). Structure and strategy in learning to talk. Monographs of the Society for Research in Child Development 38, No. 149.

- (198I). Individual differences in language development: implications for development and language. Developmental Psychology 17, 170-87. 


\section{ED I T OR I A L}

Perner, J. \& Leekam, S. R. (1986). Belief and quantity: three-year-olds' adaptation to listeners' knowledge. Fournal of Child Language 13, 305-1 5.

Peterson, C. \& Dodsworth, P. (1991). A longitudinal analysis of young children's cohesion and noun specification in narratives. Yournal of Child Language 18, 397-415.

Pine, J. M. \& Lieven, E. V. M. (1990). Referential style at thirteen months: why age-defined cross-sectional measures are inappropriate for the study of strategy differences in early language development. Fournal of Child Language 17, 625-31.

Pinker, S. (1984). Language learnability and language development. Cambridge, MA: Harvard University Press.

- ( 1989$)$. Learnability and cognition: the acquisition of argument structure. Cambridge, MA: MIT Press.

Reinhart, T. (1983). Anaphora and semantic interpretation. London: Croom Helm.

Richards, B. \& Robinson, P. (1993). Environmental correlates of child copula verb growth. Gournal of Child Language 20, 343-62.

Shatz, M., Hoff-Ginsberg, E. \& Maclver, D. (1989). Induction and the acquisition of English auxiliaries: the effects of differentially enriched input. Journal of Child Language 16, $141-60$.

Slobin, D. I. (ed.) (1985). The crosslinguistic study of language acquisition. Vols I \& II. Hillsdale, NJ: Erlbaum.

(ed.) (1993). The crosslinguistic study of language acquisition. Vol. III. Hillsdale, NJ: Erlbaum.

Snow, C. (1986). Conversations with children. In P. Fletcher \& M. Garman (eds), Language acquisition (2nd edn). Cambridge: C.U.P.

Sperber, D. \& Wilson, D. (1986). Relevance : communication and cognition. Oxford: Blackwell.

Vaidyanathan, R. (I991). Development of forms and functions of negatives in the early stages of language acquisition: a study in Tamil. Fournal of Child Language 18, $5 \mathrm{I}-66$.

Weist, R. M., Wysocka, H. \& Lyytinen, P. (1991). A crosslinguistic perspective on the development of temporal systems. Yournal of Child Language 18, 67-92.

Katharine Perera

Editor 